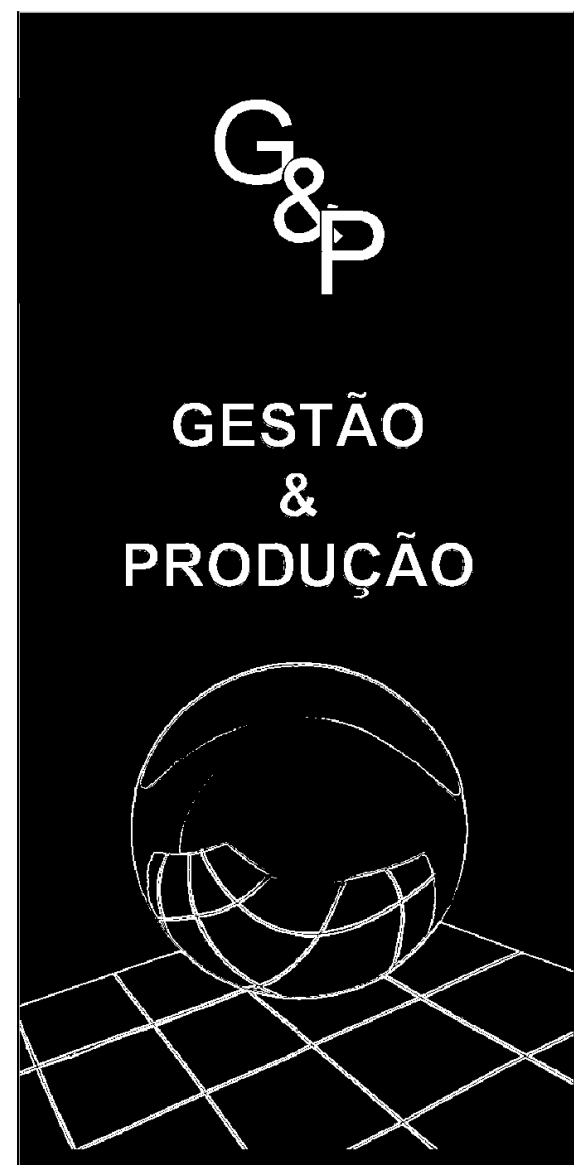

v.3, n.3, p. 290-306, dez. 1996

\section{O NÍVEL DE SERVIÇO LOGÍSTICO- PORTUÁRIO SOB A ÓTICA DOS EXPORTADORES}

\section{Antonio Galvão Novaes Hélio Flávio Vieira}

Universidade Federal de Santa Catarina Departamento de Engenharia de Produção e Sistemas

\title{
Resumo
}

A plena satisfação dos clientes/usuários tornou-se um paradigma da moderna Logística. No entanto, entidades portuárias não têm procurado avaliar de forma sistematizada as opiniões dos usuários em relação aos serviços a eles oferecidos. Neste trabalho é discutida a aplicação de técnicas de preferência declarada ou de análise conjunta para quantificar os pesos associados aos diferentes fatores que regem o nível de serviço no processo de exportação de produtos manufaturados. A metodologia é aplicada às indústrias catarinenses que vêm exportando em contêineres através dos portos do estado.

\section{Palavras-chave: nível de serviço, logística de exportação, análise conjunta.}

\section{Introdução}

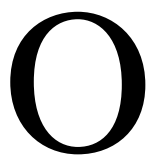

transporte de carga tradicional trata de deslocar produtos e insumos entre pontos diversos (escala espacial), considerando a escala do tempo de forma secundária. Assim, o transportador tradicional se incumbe de levar uma determinada carga de um ponto A para um ponto $\mathrm{B}$, mas geralmente não assume o compromisso de entregá-la no destino dentro de um prazo pré-estabelecido. Até alguns anos atrás o salto conceitual a partir do transporte tradicional para o serviço logístico se apoiava fundamentalmente no seguinte aspecto: para se ter um bom serviço logístico é preciso atender plenamente os compromissos pré- 
estabelecidos de prazos de entrega, considerando não somente os prazos médios, como também sua variabilidade (confiabilidade dos prazos).

O sistema produtivo resolvia, então, o problema das defasagens temporais entre fluxos de mercadorias por meio de estoques intermediários. Nos últimos anos o conceito de Logística tornou-se mais exigente e mais complexo. Hoje fica difícil, em alguns casos, separar o processo de manufatura do processo logístico. Por exemplo, automóveis japoneses são embarcados nos navios, com destino à América do Norte, ainda não completamente montados. Operários realizam esse trabalho de montagem embarcados, aproveitando o tempo - antes desperdiçado - da viagem entre o Japão e os Estados Unidos. O grande incentivo dessa prática está basicamente na postergação (postponement) do uso de um certo número de peças, que passam a ser incorporadas ao produto final (o automóvel) no último momento possível, reduzindo assim o estoque, e conseqüentemente o capital investido. Então, a separação entre manufatura e transporte, antes tão nítida, passou a ser um tanto nebulosa.

Nessa evolução continuada da Logística, vão aparecendo novas formas de encarar a estratégia empresarial, de conquistar participação e de manter-se no mercado. Por exemplo, LAMBERT (1992) acentua que, para sobreviver numa economia global, as indústrias precisam produzir a níveis de custo mais baixos, ao mesmo tempo que precisam oferecer serviços que agregam valor ao produto. Ou seja, os resultados positivos da diferenciação não são mais exclusivos de alguns competidores, mas passam a ser exigidos de todos. O cliente quer assim preços baixos ao mesmo tempo que exige qualidade.
O chamado marketing mix, que traduz a forma pela qual os recursos da empresa são alocados aos quatro "p's" (product, price, promotion, place) (INNIS et al., 1994), é determinante para a fixação do nível de satisfação do cliente, alem de ser fundamental para garantir um determinado market share para a empresa e uma rentabilidade adequada. É pelo nível de serviço ao cliente, que agrega valor ao produto vendido, que o setor de marketing e o setor de logística se integram, trabalhando juntos para melhorar a competitividade da empresa. Entender então as necessidades e preferências do cliente/usuário, de forma a melhor atendê-lo, passa a ter uma importância capital na estratégia competitiva da empresa. Quando o cliente é uma grande indústria ou grande empresa comercial, o problema é de certa forma minorado porque o consumidor exige de seus fornecedores, de forma clara e precisa, o nível de serviço requerido para suas atividades. Por exemplo, as iniciativas e acertos de just-in-time nas montadoras de veículos partem destas para os fornecedores, e esses normalmente se adaptam às exigências das primeiras tendo em vista os volumes contratados, os acordos de longo prazo, a margem certa, etc.

No caso específico das atividades portuárias, as repercussões da qualidade dos serviços na exportação de produtos transcendem o limite das relações entre empresas e clientes, pois os resultados, positivos ou negativos, têm implicações sérias nas trocas comerciais, na balança de pagamentos do País, no PIB, e no nível de emprego interno. No Brasil, a desarticulação entre os elos da cadeia logística (produtores, rodovia, ferrovia, armazenagem, portos, armadores) é acentuada, levando a custos globais elevados e tempos porta-a-porta excessivos e de baixa confiabilidade. 
O objetivo deste trabalho é discutir uma metodologia bastante utilizada no exterior (análise conjunta ou preferência declarada) na definição e quantificação do nível de serviço conforme a visão dos usuários, mostrando sua aplicação na avaliação da cadeia logística de exportação, com ênfase nos serviços portuários.

\section{Nível de Serviço Logístico}

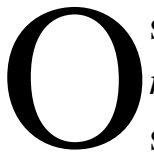

$s$ quatro "p's" que formam o marketing mix da empresa acabam sendo sentidos pelo cliente segundo três componentes específicos: o preço, a qualidade do produto ou do serviço e o nível de serviço a ele agregado. Os usuários selecionam seus fornecedores baseados numa combinação desses três componentes para satisfazer suas necessidades (BALLOU, 1993). O nível de serviço compreende todo o conjunto de atributos oferecidos ao cliente, devidamente identificados e quantificados. Por exemplo, o prazo de entrega, pré-estabelecido em 2 dias úteis para a região $\mathrm{A}, 3$ dias úteis para a região B e assim por diante. São exemplos típicos de atributos que formam o nível de serviço:

- prazo de execução dos serviços e respectivo nível de confiabilidade;

- tempo de processamento de cada tarefa;

- disponibilidade de pessoal e dos equipamentos solicitados;

- precisão no preenchimento dos pedidos e na execução dos serviços (nível de erro ou falhas)

- facilidade em sanar os erros e falhas;

- agilidade e precisão no fornecimento de informações sobre os serviços em processamento;

- agilidade e precisão no rastreamento de cargas em processamento ou em trânsito;

- agilidade e atendimento na resolução de reclamações;

- estrutura tarifária fácil de entender e simples de aplicar, etc.
No caso de serviços, a distinção entre a qualidade e o nível de serviço não é imediata em alguns casos. Entendemos por qualidade do serviço algo intrínseco à sua natureza. Por exemplo, no serviço de uma clínica médica, a qualidade estaria ligada à capacitação profissional da equipe, medida pelos casos bem sucedidos de tratamento, intervenções cirúrgicas, etc. Já o nível de serviço seria medido por atributos externos, tais como: pronto atendimento nas condições emergenciais, baixo nível de infecções hospitalares, disponibilidade de aparelhos e equipamentos, etc. No caso dos serviços portuários, embora a diferença seja mais tênue, ainda assim pode ser notada. Por exemplo, um porto como o de Antuérpia, na Bélgica, é formado não somente pelas instalações portuárias típicas, como também por um retroporto ${ }^{(1)}$ voltado à embalagem/distribuição de produtos, a processamentos semi-industriais (produção de suco de laranja enlatado a partir de suco a granel) e outras atividades que agregam valor ao produto. Somando-se a isso as operações comerciais e financeiras, chega-se a um leque de atividades que agregam maior qualidade às operações porque permitem $o$ desencadeamento de atividades industriais/comerciais mais abrangentes do que as normalmente encontradas em portos convencionais.

\footnotetext{
1 Área não pertencente diretamente à administração do porto e ocupada por atividades complementares diversas.
} 
BALLOU (1993) agrupa os fatores que compõem o nível de serviço em três categorias, segundo o período em que ocorrem, em função do momento da contratação dos serviços. Esses grupos são identificados como fatores de pré-transação, de transação e de pós-transação respectivamente. No primeiro grupo, que envolve os atributos oferecidos antes da contratação dos serviços, está compreendida principalmente a clara definição da política logística da empresa (o cliente sabe de antemão o que pode cobrar do fornecedor). Por ocasião da venda do produto ou serviço são importantes: disponibilidade de pessoal e dos equipamentos na data combinada, prazo para realização dos serviços, transparência na estrutura de custos, estrutura tarifária simples e de fácil compreensão e aplicação, etc. Finalmente, na fase pós-transação é importante o rápido atendimento das reclamações, com clara definição de responsabilidades.

No Brasil há uma certa preocupação com o cliente até o momento em que a transação se concretiza. Daí para a frente, grande parte dos serviços logísticos hoje oferecidos tendem a ficar menos eficientes, lutando o usuário para ser atendido e para obter informações sobre o processamento de sua solicitação.

\section{Posicionamento Estratégico dos Portos}

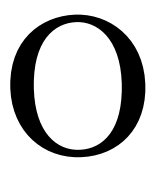

s serviços portuários foram regulamentados, no Brasil, na década de 30, por Decreto Federal cuja estrutura está ainda hoje presente na operação dos portos brasileiros. O principal aspecto desse decreto, e que desejamos destacar, é a conceituação da forma de prestação dos serviços, contida naquele documento legal. Os portos organizados são entidades dotadas de instalações, pessoal, e equipamentos à disposição dos usuários, devendo atendê-los com isonomia, sem preferências ou privilégios. Ou seja, o porto deve atender os que estão na fila esperando pelo serviço. Observa-se, no entanto, uma ação insuficiente das administrações portuárias no sentido de melhor disciplinar o atendimento, e reduzir rapidamente as filas quando ultrapassam os limites do normal.

Há pouco ouvimos reclamações no porto de Mucuripe, em Fortaleza, CE, sobre a dificuldade em organizar as chegadas de navios ao porto, cuja contratação e programação são feitas de forma desarticulada pelos shippers, sem nenhuma consulta à entidade portuária, que não dispõe de nenhum instrumento que lhe dê condições de organizar tais atividades. Nos terminais de carga especializada (granéis, contêineres, derivados de petróleo), o número reduzido de berços requer uma programação mais estruturada, sob pena de não conseguir índices de aproveitamento satisfatórios. É comum também nos terminais de contêineres a permanência ociosa de navios à espera de unidades, que só à última hora são levadas ao costado do navio pelos embarcadores.

Suponhamos, para exemplificar, que dois navios porta-contêineres estejam-se aproximando de um terminal portuário especializado, dotado dos melhores equipamentos e oferecendo os melhores serviços. Suponhamos que o primeiro navio a chegar seja uma embarcação antiga, com 20 contêineres estivados nas cobertas, enquanto a segunda seja um portacontêineres moderno, de linha regular, com um carregamento completo de contêineres 
para desembarcar e outro carregamento expressivo a ser embarcado. Pelas regras oficiais a entidade portuária deveria atender primeiro o navio obsoleto, pois chegou antes (first-come, first-served), fazendo o outro esperar ao largo. Ora, tal procedimento levaria as empresas de navegação a não oferecer serviços de transporte marítimos diferenciados aos importadores/exportadores daquela região, resultando em vantagens comparativas menores para a economia do País a médio e longo prazo.

Assim, os portos nacionais precisam partir para uma participação mais agressiva e atuante, ajudando a melhorar nossa participação competitiva no comércio internacional. Para isso os portos nacionais devem aperfeiçoar-se de duas formas diversas e complementares. De um lado, voltados para fora, o objetivo será o de pôrse em consonância com os avanços operacionais e tecnológicos observados em portos de natureza semelhante, situados no exterior. Tal prática permitirá que serviços de navegação de melhor qualidade e mais econômicos sejam atraídos para atender nossos importadores/exportadores. De outro lado, voltados para dentro, a meta será a de melhorar o nível de serviço oferecido aos usuários, ao mesmo tempo reduzindo os cusẤbogística coloca a satisfação do cliente como um paradigma fundamental. Sua importância cresceu tanto no domínio empresarial, que ela vem sendo encarada por muitas organizações não mais como um centro de custos, mas sim como uma unidade de negócios. Está aumentando o número de empresas que desenvolvem e aperfeiçoam seus serviços logísticos para uso próprio, oferecendo-os logo depois para outras firmas, numa nova atividade comercial. Outras empresas, como é o caso da indústria Becton-Dickinson, fabricante multinacional de seringas descartáveis e outros produtos médico-farmacêuticos, têm usado a Logística como instrumento de ampliação de suas vendas e de maior satisfação para seus clientes. Por exemplo, constatando que muitos de seus clientes tinham dificuldade em implementar um sistema de código de barras para uso próprio, a Becton-Dickinson incorporou uma estrutura de informações ao seu próprio sistema, informações essas de interesse direto de seus clientes. Estes, ao receber as embalagens com os produtos, podem processar e controlar seus fluxos e estoques utilizando as mesmas etiquetas de barras afixadas pelo fornecedor.

A bibliografia de Logística vem apresentando um número crescente de artigos e pesquisas voltados à questão da plena satisfação dos clientes/usuários dos serviços logísticos. Citamos, por exemplo, os trabalhos de LAMBERT (1990, 1992), MANRODT et al. (1992), e INNIS et al. (1994). Específicos sobre as preferências e posicionamento dos usuários de portos, destacam-se os trabalhos de MURPHY et al. (1992) e de VIEIRA (1996).

Formas diversas são utilizadas para analisar e medir as reações dos usuários às variações no nível de serviço a eles oferecidos. Vamos nos concentrar especificamente numa dessas técnicas, que vem sendo muito utilizada no exterior e com aplicações as mais diversas. Trata-se das técnicas de preferência declarada (stated preference techniques) ou de análise conjunta (conjoint analysis). O primeiro nome é adotado em estudos de transportes, enquanto o segundo é mais utilizado em marketing. No fundo ambas as técnicas são praticamente equivalentes, mudando apenas os métodos de calibração e as aplicações. É comum, por exemplo, calibrar os modelos 
de conjoint analysis por meio de regressão múltipla, enquanto os modelos de stated preference usam o processo de maximização de uma função de verossimilhança.

\section{Preferência, Comportamento e Atitude}

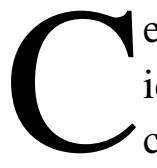

ertos tipos de evento permitem identificar claramente os componentes da ação do consumidor em relação a um determinado produto ou serviço. Assim, quando o cliente vai a uma loja e adquire um televisor, podemos registrar os dados sócioeconômicos relevantes (faixa de renda, grau de instrução, faixa etária, sexo) e, por outro lado, as características do produto adquirido, bem como a forma de pagamento. Uma vez que a compra se realizou de fato, os dados assim coletados refletem o comportamento real do consumidor ante o leque de opções oferecido. É claro que pode haver distorções na interpretação dos resultados em certos casos. Por exemplo, em fases de grande escassez de oferta, o consumidor poderá adquirir um produto ou serviço diferente daquele originalmente desejado. Em épocas de inflação acelerada, a expectativa de aumento de preços pode antecipar uma aquisição e deixar o comprador/usuário menos resistente a diferenças locais de preço, etc.

No caso de serviços (entre eles incluído o serviço logístico) os atributos envolvidos são mais tênues, e o consumo do serviço pode se dar ao longo de um certo intervalo de tempo (e não num certo momento específico, como é o caso da compra de um produto), mas ainda assim é possível analisar e compreender o comportamento do usuário ou consumidor. Mas nem sempre o comportamento real do consumidor é suficiente para analisar todo o leque de fatores que compõem o nível de serviço. Uma forma de contornar essas limitações é realizar experimentos de campo (pesquisas) envolvendo as preferências do consumidor. Isto é, registram-se informações obtidas nas entrevistas em que o consumidor em potencial indica escolhas hipotéticas que ele faria em determinadas situações. Para isso é necessário lançar mão de técnicas especiais para evitar que o entrevistado vicie as respostas de forma consciente ou mesmo subjetiva.

Esse tipo de enfoque permite: (a) analisar algumas situações hoje não existentes, uma vez que é impossível conseguir dados comportamentais reais sobre elas; (b) melhor explorar combinações de atributos e sua variabilidade, já que, na vida real, as combinações observadas ocorrem em menor núñerfijg.1 é mostrado esquematicamente o processo mental do consumidor com relação a um determinado produto ou serviço a ser adquirido. O processo é condicionado pelas características próprias do indivíduo, pelos atributos das alternativas disponíveis para sua escolha, e pelas informações do mercado (propaganda, promoções, etc). Num nível mais recôndito de sua mente, o consumidor registra suas percepções em relação ao problema, sendo essas percepções subjetivas, relacionando-se mais diretamente com as atitudes.

São consideradas atitudes manifestações dos indivíduos baseadas fundamentalmente em fatores subjetivos. Um exemplo refere-se ao sistema de metrô, que sofre rejeição por parte de pessoas analfabetas, que não conseguem ler os nomes das estações e ficam inseguras quanto ao local onde devem desembarcar. Uma vez conhecidas as atitudes e suas causas, pode-se removê-las 
ou minimizar seus efeitos por meio de medidas específicas. Por exemplo, a distinção das diversas estações por meio de tipos diversos de acabamento, cores, etc ajuda na sua identificação, além de melhorar esteticamente a paisagem.

Já num nível mais consciente do processo mental (Fig. 1), o consumidor manifesta sua preferência em relação ao produto ou serviço em questão. Ainda não se trata de uma ação concreta, mas o consumidor em potencial já consegue exteriorizar e justificar uma posição de forma mais clara e mais objetiva. Por exemplo, um cidadão que pretende viajar à Europa a negócios, diz a seus colegas que prefere voar na classe executiva, justificando a despesa adicional com uma série de argumentos, como, por exemplo, a maior disposição para o trabalho no destino, etc. É claro que ainda existem fatores subjetivos nessa exteriorização de preferências. É possível que o executivo do exemplo esteja subjetivamente considerando o fator status, levando em conta que seus colegas de mesmo nível, de outras empresas, gozam desse privilégio. Pode acontecer também que, na hora de adquirir a passagem aérea, acabe optando pela classe econômica por sugestão da esposa ou por decisão de seu chefe na firma em que trabalha. Assim, a manifestação da preferência não garante a realização efetiva do evento, mas há uma correlação bastante forte entre ambas.
Quando chega finalmente a hora da ação o consumidor opta finalmente, escolhendo uma das alternativas disponíveis. Seu ato, nesse momento, juntamente com os fatores que lhe deram elementos para decidir, é denominado de comportamento. Nem nesse momento sua decisão está totalmente livre de fatores subjetivos, mas predominam agora fatores mais racionais, tais como preço, qualidade, atendimento, etc.

Consideramos assim como comportamento o processo de decisão que envolve situações realmente concretizadas (uma compra, o uso efetivo de um certo serviço) e que seja explicado, ainda que não totalmente, por fatores racionais de compreensão geral, tais como preço, rapidez, qualidade, etc. Entendemos como preferência os atos que refletem possíveis decisões, não realizadas concretamente mas explicitamente declaradas, envolvendo escolhas alternativas realistas. As alternativas devem ser realistas porque o ser humano, tendo a faculdade de pensar e de divagar, pode imaginar situações as mais improváveis. Por exemplo, nada impede de que sonhemos com a compra de um Learjet para uso particular, em que pese a probabilidade bastante baixa desse evento. A manifestação de preferência inclui ainda componentes racionais, mas em menor escala do que o comportamento real efetivamente adotado. 


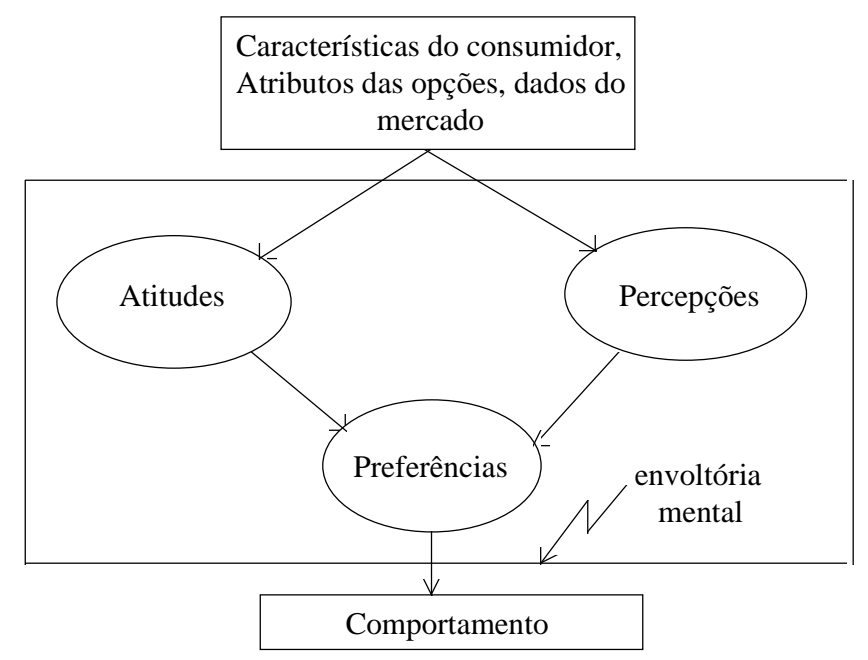

Fig. 1: Processo Mental do Usuário/Consumidor

É sabido que a manifestação das preferências por parte do consumidor pode não se concretizar na prática, ou pode verificar-se apenas em parte no momento da decisão efetiva da aquisição do produto ou do serviço. No entanto, os experimentos baseados no levantamento das preferências dos consumidores tendem a ser mais ricos em informação, pois possibilitam melhor exploração das possibilidades e das combinações dos atributos. Uma forma de contornar esse problema é ajustar um modelo explicativo para as preferências, recalibrando-o posteriormente em confronto com as informações disponíveis sobre casos reais.

\section{Técnicas de Preferência Declarada}

$\mathrm{H}$

á diversos métodos para analisar e medir as reações dos usuários aos elementos ou atributos que formam o nível de serviço portuário. O trabalho de MURPHY et al. (1992), por exemplo, baseia-se em pesquisas realizadas por intermédio do correio, num total de aproximadamente 400 questionários aproveitados, sendo os dados posteriormente tratados estatisticamente de forma a fornecer os fatores (ou pesos) associados aos diversos atributos. Neste texto vamos apresentar um estudo semelhante, elaborado em relação aos portos catarinenses, e utilizando técnica de preferência declarada ou de análise conjunta (NOVAES, 1995; VIEIRA, 1996). Vamos descrever rapidamente os principais aspectos relacionados com esse método.
A maneira convencional de analisar o comportamento dos usuários de transportes consiste em utilizar os métodos de preferência revelada (PR), que se baseiam nas decisões dos indivíduos já realizadas num passado recente. Os dados são obtidos, nos estudos de PR, mediante observação direta no campo, ou por meio de entrevistas em que se pede à pessoa que relate seus deslocamentos realizados, digamos, na véspera. Os métodos de $\mathrm{PD}$, por sua vez, formam uma família de técnicas que trabalham com as preferências dos entrevistados, preferências reveladas pela escolha, por parte do consumidor ou usuário, de alternativas selecionadas a partir de um conjunto de opções. Os dados resultantes são utilizados para ajustar funções-utilidade. 
Os métodos de PD apresentam algumas vantagens sobre as técnicas tradicionais do tipo PR:

(a)Ajuste estatístico: nas pesquisas tradicionais existe pouco controle sobre o alcance dos dados e sobre sua variabilidade. Em primeiro lugar, nas condições reais, muitos atributos variam de forma mais ou menos correlacionada (o problema da colinearidade em econometria), como, por exemplo, nível de conforto e preço. Assim, muitas vezes não se consegue separar, na análise, os efeitos dessas variáveis na demanda. Nos experimentos tipo $\mathrm{PD}$, ao contrário, os níveis das variáveis podem ser escolhidos independentemente, desde que as situações resultantes não se afastem demasiadamente das condições reais. Em outras palavras, o analista pode definir antecipadamente a estrutura fatorial de

(b) Seaveaxpsirinaçcôtex: desde que as pessoas entrevistadas sejam suficientemente esclarecidas sobre as características de um novo serviço, juntamente com suas vantagens e desvantagens, é possível criar alternativas hipotéticas, porém realistas, e apresentá-las nas pesquisas. É claro que isso não é possível com dados obtidos por meio de casos efetivamente realizados (situações concretas, tipo PR).

(c)Tipos de variáveis: em pesquisas do tipo PD trabalhamos muitas vezes com variáveis de natureza qualitativa, como conforto, atendimento, acessibilidade, etc. Nos experimentos de PD torna-se mais fácil definir tais variáveis e montar cenários em que a diferenciação das diversas situações torna-se mais explícita. Numa entrevista típica de PD as informações são fornecidas ao entrevistado por meio de cartões. É comum apresentar cerca de cinco a nove cartões aos entrevistados. Os cartões devem conter, sempre que possível, informações na forma de figuras ou fotos, complementadas com os números apropriados e informações qualitativas. Todas as informações devem ser de fácil compreensão e utilizar nomenclatura e medidas de uso comum pelos entrevistados. Estes são solicitados, após os esclarecimentos e perguntas iniciais, a exercer suas opções em relação às situações apresentadas. Embora as escolhas dos entrevistados possam ser realizadas de maneiras diversas, as pesquisas do tipo PD por nós realizadas seguem o procedimento de ordenação dos cartões (ranking procedure). Os cartões são apresentados numa sequiência aleatória ao entrevistado e este escolhe a opção que mais lhe agradar. Esse cartão é então retirado do conjunto, e o entrevistado faz sua segunda opção, e assim sucessivamente. Sendo $m$ o número de cartões, tem-se ao fim $m-1$ escolhas diversas. Adotando-se um modelo logit multinomial para as probabilidades de escolha (BEN-AKIVA \& LERMAN, 1985), procede-se ao ajuste de uma função utilidade tomando-se as $n(m-1)$ decisões, onde $n$ é o número de entrevistas e $m$ o número de cartões oferecidos aos entrevistados. O desdobramento do processo de escolha em $m-1$ decisões independentes por parte de cada entrevistado leva a um modelo denominado logit explodido. Os princípios que norteiam esse enfoque são discutidos por CHAPMAN \& STAELIN (1982).

Uma vez que são comuns pesquisas com vários atributos, cada um com dois ou três níveis, a estrutura fatorial resultante pode tornar-se muito grande. É comum, nestes casos, agrupar os cartões em blocos, distinguindo-os por cores (de fundo) diversas. $O$ bloco de cartões a ser apresentado a um entrevistado deve ser 
então extraído aleatoriamente do conjunto de blocos disponíveis. A estruturação das pesquisas segue as regras estatísticas de delineamento de experimentos fracionais, em blocos.

\section{Medindo as Preferências dos Usuários}

$\mathrm{O}$ estudo foi centrado no parque exportador catarinense, especificamente nas empresas que enviam seus produtos ao exterior em contêineres. As indústrias catarinenses se localizam em pólos produtores bem definidos, que são: a região agro-industrial no oeste, o setor têxtil no Vale do Itajaí, a indústria cerâmica ao sul, o setor eletrometal-mecânico no nordeste, e o setor moveleiro ao norte do estado. A participação relativa dos diversos setores industriais nas exportações de Santa Catarina é mostrada no Quadro 1.

Do total de 58.221 contêineres movimentados na exportação pelos portos catarinenses de Itajaí e de São Francisco do Sul em 1994, parcela significativa $(77,5 \%)$ correspondeu às empresas catarinenses. Os pólos industriais localizados em Joinville, São Bento do Sul, Blumenau, Jaraguá do Sul e Criciúma são, juntos, responsáveis por $72,2 \%$ de todas as mercadorias conteinerizadas destinadas ao comércio exterior através dos portos de Itajaí e São Francisco do Sul no ano de 1994. Aproximadamente $70 \%$ de toda a movimentação de contêineres de Santa

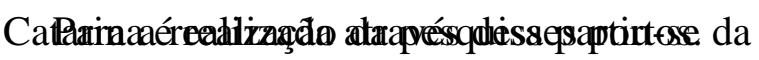
classificação das 40 maiores empresas exportadoras catarinenses, amostrando-se dessa lista 10 indústrias, de forma a representar adequadamente os diversos setores industriais de interesse para a economia do estado. O conjunto dessas dez empresas representa $55,6 \%$ do movimento de contêineres exportados.
Inicialmente foram definidos os atributos ou variáveis que formam o nível de serviço. Com base num questionário preliminar encaminhado a 20 empresas representativas (índice de resposta de 75\%) foram identificados os seguintes fatores:

1) custo terrestre: englobando as despesas do transporte da fábrica ao porto, mais as despesas portuárias até o embarque no navio (custo FOB, em US\$/conteiner de 20 pés);

2) frete marítimo: valor da tarifa do transporte marítimo (US\$/conteiner de 20 pés), já levando em conta eventuais descontos, dependendo da região de destino (costa leste dos Estados Unidos ou norte da Europa);

3) periodicidade dos navios: representada pelo intervalo médio entre passagens consecutivas dos navios que oferecem praça para uma determinada região do globo;

4) tempo porta a porta: representando o tempo total de deslocamento da carga desde a fábrica até o destino final no exterior;

5) segurança no porto: referente à integridade da carga no porto (ausência de roubos e violações dos contêineres, ausência de extravios e de problemas

6) simdingẽs\$; de atendimento no porto: refletindo a maior ou menor ocorrência de entraves burocráticos, disponibilidade de equipamentos e de pessoal, respostas inadequadas às reclamações, etc;

7) outras características do porto não incluídas nos demais atributos. 
Para gerar os diversos "cenários" que seriam representados nos cartões a serem submetidos às empresas entrevistadas, era necessário definir os níveis de variação dos sete atributos considerados.

Para os seis primeiros atributos foram definidos dois níveis para cada variável: um nível 0 , representando a condição atual, e um nível 1 representando uma situação típica melhorada. O último atributo é formado por variável 0-1, do tipo dummy (no sentido econométrico), representando os três portos catarinenses de interesse: Itajaí,
São Francisco do Sul e Imbituba, e tendo portanto três níveis. O conjunto de 7 atributos, com os respectivos níveis, leva a um experimento fatorial do tipo $2^{6} 3^{1}$, que apresenta 192 combinações possíveis. Adotou-se um experimento fracional, com vinte blocos, cada um deles constituído por 9 cartões (Mc LEAN \& ANDERSON, 1984). Para cada empresa entrevistada (num total de 10 empresas) foram selecionados aleatoriamente dois blocos do conjunto, sem repetição.

\section{Quadro 1}

Participação dos Setores Industriais nas Exportações Catarinenses (1995)

\section{Fonte: SECESX/DIRT}

\begin{tabular}{|l|c|}
\hline Setor Industrial & Participação (\%) \\
\hline Eletro-metal-mecânico & 18,81 \\
Aves, suinos, embutidos & 16,11 \\
Madeira e beneficiados & 10,64 \\
Têxteis & 9,25 \\
Soja e farelo & 7,89 \\
Fumo & 4,16 \\
Papel & 4,14 \\
Cerâmico & 3,91 \\
Óleo de soja & 3,79 \\
Açúcar refinado & 1,74 \\
Couro & 0,62 \\
Outros & 18,94 \\
\hline Total: & 100,00 \\
\hline
\end{tabular}

Foram entrevistados nas empresas selecionadas os responsáveis pelos respectivos setores de exportação. Após os esclarecimentos iniciais sobre o objetivo da entrevista (as empresas já haviam sido contactadas na pesquisa preliminar anterior), era apresentado o primeiro bloco de cartões ao entrevistado. A pessoa entrevistada, após examinar cuidadosamente os cenários contidos nos 9 cartões, selecionava aquele que lhe parecia ser a melhor alternativa para sua empresa. Uma vez anotada a opção e 
extraído do bloco o cartão escolhido, passava o entrevistado a fazer sua segunda melhor opção, e assim sucessivamente. Ao fim, restando apenas dois cartões no conjunto, o entrevistado fazia sua última opção, restando assim um cenário rejeitado. Esse procedimento em série, de múltipla escolha, era repetido para o segundo bloco de cartões. Cada bloco representa 8 escolhas (igual ao número de cartões menos um), totalizando então 16 manifestações de preferência em cada entrevista, ou 160 no total da amostra (10 empresas entrevistadas). Esse esquema de escolhas encadeadas, definidas a partir de um experimento estatístico, é muito rico em informações sobre as preferências das empresas exportadoras. Para a representação matemática adotou-se uma função utilidade linear (BEN-AKIVA \& LERMAN, 1985):

$$
U_{i}=\beta_{1} x_{1}+\beta_{2} x_{2}+\beta_{3} x_{3}+\ldots+\beta_{8} x_{8}
$$

onde $U_{i}$ é a utilidade associada ao "cenário" $\mathrm{i}, x_{k}$ é o valor do atributo $k(k=1,2,3 \ldots)$ para esse cenário, sendo $\beta_{k}$ coeficientes a serem determinados por calibração (ajuste estatístico). Nesta aplicação os atributos foram considerados de forma transformada, a saber: (a) os atributos $x_{1}$ e $x_{2}$, representando respectivamente os custos terrestres e o frete marítimo, foram considerados de forma diferencial em relação às condições atuais enfrentadas pela empresa (diferença entre o custo mostrado no cartão e o custo atualmente praticado), e dividindo-se esse resultado pelo valor médio da carga contida num conteiner cheio: (b) os atributos $x_{3}$ e $x_{4}$, que representam respectivamente a freqüência de navios e o tempo total porta a porta, foram também considerados de forma diferencial (diferença entre o tempo mostrado no cartão e o tempo atualmente observado); (c) finalmente os atributos ordinais restantes $\left(x_{5}, x_{6}, x_{7}\right.$ e $\left.x_{8}\right)$ foram representados por variáveis tipo zeroum. As variáveis $x_{7}$ e $x_{8}$ conjuntamente representam o sétimo atributo (3 níveis) por meio das combinações $(0,0),(1,0)$ e $(0,1)$. Assim, tem-se ao todo 7 atributos, representados por 8 variáveis.

Um modelo de escolha discreta do tipo logit multinomial (BEN-AKIVA \& LERMAN, 1985) foi ajustado aos dados levantados nas entrevistas:

$$
p_{i k}=\frac{\exp \left(U_{i k}\right)}{\sum_{j} \exp \left(U_{j k}\right)}
$$

onde $p_{i k}$ é a probabilidade de o entrevistado, no experimento de ordem k, indicar a opção $i$. O ajuste do modelo é realizado mediante um processo vetorial de Newton-Raphson (DIXON, 1972) que maximiza a função log-verossimilhança, fornecendo os valores dos coeficientes $\beta_{k}$ $(\mathrm{k}=1,2, \ldots)$. A função de verossimilhança é dada POR (BEN-AKIVA \& LERMAN, 1985):

$$
\max \Lambda=\max \prod_{k} \prod_{i}\left[\frac{\exp \left(U_{i k}\right)}{\sum_{j} \exp \left(U_{j k}\right)}\right]^{y_{i k}}
$$

onde $y_{i k}=1$ se a alternativa $i$ foi escolhida no experimento $k$, sendo zero em caso contrário. Normalmente se trabalha com a função log-verossimilhança, cujo ponto de máximo (por ser função monotonicamente 
crescente) coincide com o da função (3). Aplicando logaritmos naturais:

$$
\max \ln \Lambda=\max \sum_{k} \sum_{i} y_{k i}\left(U_{i k}-\ln \sum_{j} \exp \left(U_{j k}\right)\right)
$$

O objetivo do processo de maximização da função log-verossimilhança é determinar os valores dos coeficientes $\beta_{k}(k=1,2,3 \ldots)$ da função utilidade (1).

À exceção do atributo "segurança", todos os demais fatores foram estatisticamente significantes ao nível de $99 \%$ (estatística $t$ de Student). A explicação para tal fato devese à proteção que naturalmente o conteiner confere à carga nele estivada, o que torna esse atributo de pouca expressão para os entrevistados. Essa é uma situação específica do transporte em contêineres, e que certamente não ocorreria com a carga geral convencional. Assim o fator "segurança no porto" foi excluído da função utilidade e, dessa forma, dos 7 atributos iniciais, restaram 6. Os resultados do ajuste estatístico são apresentados no Quadro 2. Além da estatística t, o parâmetro -2[ $\ell(0)$ - $\ell(\beta)$ ] (onde $\ell(0)$ representa o valor da função log-verossimilhança para $\beta_{1}=\beta_{2}=\ldots=0$ e $\ell(\beta)$ representa o valor otimizado da função log-verossimilhança) serve para testar a hipótese nula global de que todos os coeficientes sejam simultaneamente iguais a zero. Essa estatística é distribuída assintoticamente segundo uma distribuição "chi-quadrado", com 8 graus de liberdade (número de coeficientes a ajustar, cf. Quadro 2). O valor resultante de 82,80 indica que se pode rejeitar a hipótese nula ao nível de significância de 99\%. No Quadro 2 são apresentadas também as elasticidades da escolha dos usuários em relação às variáveis cardinais do modelo, observando-se que todas apresentam os sinais algébricos esperados e valores consistentes.

\section{Nível de Serviço Avaliado pelos Usuários}

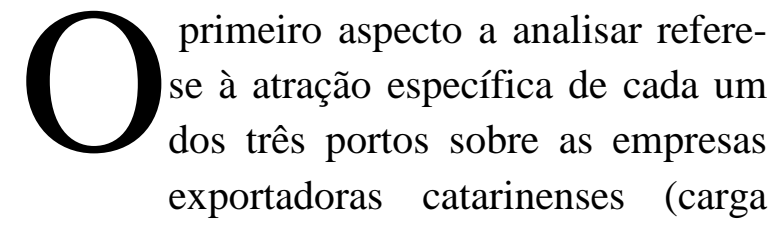
em contêineres). Suponhamos, para efeito de raciocínio, que os três portos apresentassem exatamente os mesmos valores dos parâmetros quantitativos e as mesmas características qualitativas. Sejam então $U_{S F S}, U_{I T A}$ e $U_{I M B}$ as utilidades associadas aos portos de S. Francisco do Sul, Itajaí e Imbituba respectivamente. Essas utilidades são dadas pelas seguintes expressões:

$$
\begin{gathered}
U_{S F S}=\left(\beta_{1} x_{1}+\ldots+\beta_{5} x_{5}\right)+\beta_{6} \\
U_{I T A}=\left(\beta_{1} x_{1}+\ldots+\beta_{5} x_{5}\right)+\quad+\beta_{7} \\
U_{I M B}=\left(\beta_{1} x_{1}+\ldots+\beta_{5} x_{5}\right)+\quad+\beta_{8}
\end{gathered}
$$


A probabilidade associada a cada uma dessas alternativas é dada pelo modelo
Logit. Para o caso do porto de São Francisco do Sul, por exemplo:

$$
p_{S F S}=\frac{\exp \left(U_{S F S}\right)}{\exp \left(U_{S F S}\right)+\exp \left(U_{I T A}\right)+\exp \left(U_{I M B}\right)}
$$

Observa-se então que, se os valores dos atributos $x_{1}, x_{2} \ldots, x_{5}$ forem mantidos constantes para as três alternativas (coeteris paribus $)$, o fator $\exp \left(\beta_{1} x_{1}+\ldots+\beta_{5} x_{5}\right)$ pode ser cancelado do numerador e do denominador da expressão (8), o mesmo ocorrendo com as demais probabilidades.

$$
p_{S F S}=\frac{\exp \left(\beta_{6}\right)}{\exp \left(\beta_{6}\right)+\exp \left(\beta_{7}\right)+\exp \left(\beta_{8}\right)}
$$

e, de forma análoga, para as demais opções.

Os valores dos coeficientes "dummy" $\beta_{6}, \beta_{7} e \beta_{8}$, referentes aos portos, são apresentados no Quadro 2. Aplicando o modelo Logit (9) para essa situação, encontramos as probabilidades de atração iguais a 0,455 para o porto de S. Francisco
Ou seja, nesse caso hipotético em que todos os atributos apresentam os mesmos valores em cada uma das alternativas, a probabilidade de atração será dependente apenas dos coeficientes "dummy" $\beta_{6}, \beta_{7}$ e $\beta_{8}$ :
- Porto de S. Francisco do Sul:

- Porto de Itajaí:

- Porto de Imbituba: do Sul, 0,377 para Itajaí e 0,168 para o porto de Imbituba. Atribuindo o nível 100 a São Francisco do Sul, e mantendo a proporcionalidade em relação às probabilidades, temos as seguintes atrações relativas para cada um dos três portos considerados:

Quadro 2

Resultados do Ajuste da Função Utilidade

\begin{tabular}{|l|c|c|c|}
\hline \multicolumn{1}{|c|}{ Variáveis } & Coeficientes & $\begin{array}{c}\text { Erro } \\
\text { Assintótico }\end{array}$ & Estatística t \\
\hline Custo terrestre & $-0,2476$ & 0,0137 & $-17,99$ \\
Frete marítimo & $-0,2694$ & 0,0262 & $-10,29$ \\
Freqüiência dos navios & $-0,1261$ & 0,0245 & $-5,17$ \\
Tempo porta a porta & $-0,1157$ & 0,0188 & $-6,09$ \\
Atendimento no porto & 0,1404 & 0,0897 & 1,51 \\
Porto de São Francisco (dummy) & 0,7188 & 0,0886 & 8,12 \\
Porto de Itajaí (dummy) & 0,5266 & 0,0843 & 6,32 \\
Porto de Imbituba (dummy) & $-0,2765$ & 0,0889 & $-3,13$
\end{tabular}




\begin{tabular}{|l|c|l|l|}
\hline Resultados estatísticos: & 160 & & \\
Número de Observações & 720 & & \\
Número de Casos & $-256,04$ & & \\
$\ell(0)$ & $-214,63$ & & \\
$\ell(\beta)$ & 82,80 & & \\
$-2[\ell(0)-\ell(\beta)]$ & 0,162 & & \\
$\rho^{2}$ & 0,130 & & \\
$\bar{\rho}^{2}$ & & & \\
\hline Elasticidade da demanda em relação & $-0,335$ & & \\
$\bullet$ ao custo terrestre & $-0,230$ & & \\
$\bullet$ ao frete marítimo & $-0,184$ & & \\
$\bullet$ à frequiência dos navios (intervalo) & $-0,243$ & & \\
$\bullet$ ao tempo total porta a porta & & \\
\hline
\end{tabular}

Nota: (1) Os portos são representados pelas combinações de duas variáveis binárias zero-um, conforme texto, levando a um total de 6 atributos e 7 variáveis. (2) Em relação à variável "atendimento no porto", por ser discreta, não se aplica o conceito de elasticidade, razão pela qual ela não consta do quadro.

Os valores das atrações relativas constituem elementos importantes para as administrações portuárias, para o poder público concedente, e para as entidades de classe empresariais e trabalhistas, pois traduzem o grau de satisfação dos usuários com os serviços portuários, além dos efeitos dos atributos diretamente perceptíveis. No presente exemplo, o baixo nível de atração de Imbituba se deve a uma série de fatores negativos, largamente divulgados pela imprensa, e que estão ligados a problemas de gestão do porto, hoje administrado por um grupo financeiro localizado no Rio de Janeiro. Ou seja, o modelo refletiu acuradamente o que vem sendo observado na prática.

Em seguida, e considerando as empresas de cada setor industrial, e com as respectivas características da carga e de preferência, foram calculados os pesos que formam o nível de serviço do processo de exportação, nível de serviço esse visto segundo o ponto de vista dos usuários. Os resultados são indicados no Quadro 3 e na Fig. 2.

\section{Quadro 3}

\section{Pesos dos Atributos que Formam o Nível de Serviço Conforme os Setores Industriais}

\begin{tabular}{|l|c|c|c|c|c|c|}
\hline$\underline{\text { Atributo } \rightarrow}$ & $\begin{array}{c}\text { Custo } \\
\text { Terrestre }\end{array}$ & $\begin{array}{c}\text { Frete } \\
\text { Marítimo }\end{array}$ & $\begin{array}{c}\text { Freq. dos } \\
\text { Navios }\end{array}$ & $\begin{array}{c}\text { Tempo } \\
\text { Porta a } \\
\text { Porta }\end{array}$ & $\begin{array}{c}\text { Atendi- } \\
\text { mento }\end{array}$ & Total \\
\hline Eletro-Mecânico & 18,9 & 20,5 & 9,0 & 41,5 & 10,1 & 100,0 \\
Têxtil & 14,4 & 15,7 & 10,4 & 47,9 & 11,6 & 100,0 \\
\hline
\end{tabular}




\begin{tabular}{|l|r|r|r|r|r|r|}
\hline Cerâmico & 35,5 & 38,5 & 3,9 & 17,8 & 4,3 & 100,0 \\
Moveleiro & 18,2 & 19,7 & 9,3 & 42,5 & 10,3 & 100,0 \\
\hline
\end{tabular}

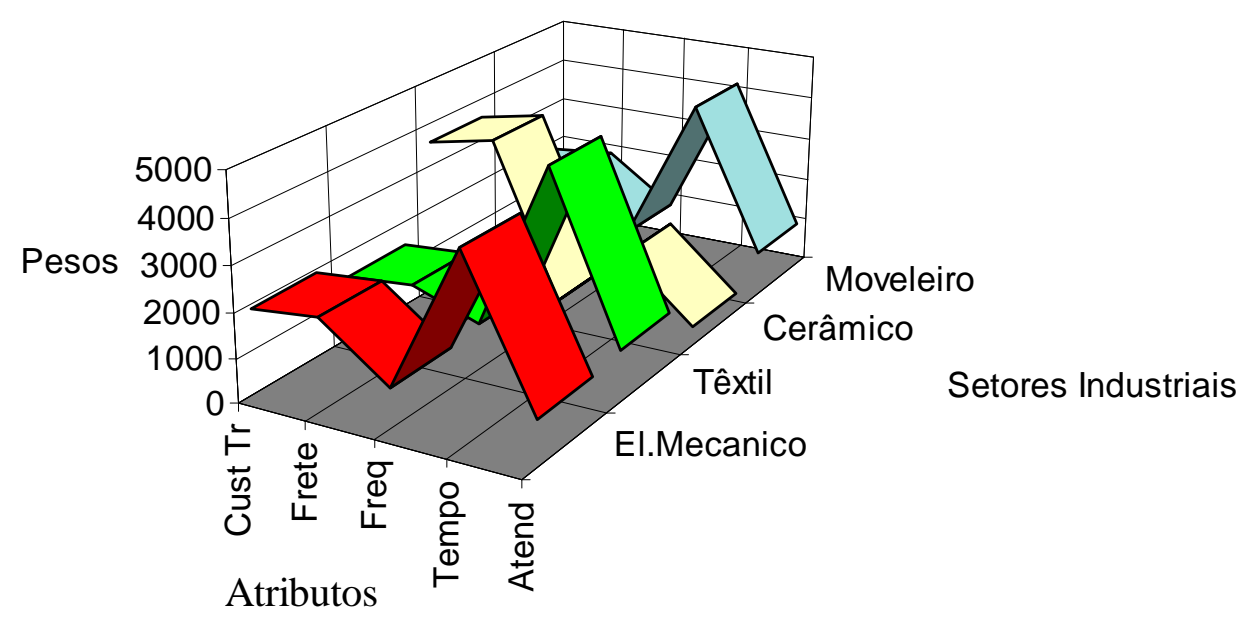

Fig. 2: Pesos que formam o nível de serviço, segundo o setor industrial

Pode-se observar que os setores industriais que apresentam valores unitários mais elevados para seus produtos, como os setores eletro-mecânico, têxtil e moveleiro, atribuem peso expressivo ao tempo de deslocamento porta a porta. Já o setor cerâmico, cujos produtos apresentam menor valor unitário, valoriza prioritariamente os itens diretamente relacionados com custos (parte terrestre e frete marítimo). Esses resultados estão bastante coerentes com o diretamente observado junto às empresas.
Os resultados de um trabalho deste tipo servem para orientar as administrações portuárias no sentido de melhor atender seus usuários, como também ao próprio setor produtivo, fornecendo-lhes argumentos para lutarem por melhor nível de serviço no processo de exportação. A metodologia empregada, baseada em técnica de preferência declarada ou de análise conjunta, mostrou-se apropriada e robusta, apresentando resultados confiáveis e estatisticamente significantes.

\section{Referências Bibliográficas:}

BALLOU, R.H.: Logística Empresarial, Editora Atlas, São Paulo, SP, 1993.

BEN-AKIVA, M. \& LERMAN, S.R.: Discrete Choice Analysis: Theory and Application to Travel Demand, The MIT Press, Cambridge, Massachusetts, 1985.

CHAPMAN, R.G. \& STAELIN, R.: "Exploiting Rank Ordered Choice Set Data Within the Stochastic Utility Model", Journal of Marketing Research, vol. 19, pp. 288-301, 1982.
DIXON, L.C.W.: Nonlinear Optimization, The English University Press, Londres, Inglaterra, 1972.

EIGLIER, P.; LANGEARD, E. \& DAGEVILLE, C.: "La Qualité de Services", Revue Française du Marketing, vol. 121, n. 1, pp. 93-100, 1989.

INNIS, D.E. \& LaLONDE, B.J.: "Customer Service: The Key to Customer Satisfaction, Customer Loyalty, and Market Share", Journal of Business Logistics, vol. 15, n. 1, pp. 1-27, 1994. 
LAMBERT, D.M.: "Developing a Costumer-focused Logistics Strategy", International Journal of Physical Distribution \& Logistics Management, Vol. 22, N 6, pp. 12-19, 1992.

LAMBERT, D.M. \& SHARMA, A.: “A Costumerbased Competitive Analysis for Logistics Decisions", International Journal of Physical Distribution \& Logistics Management, Vol. 20, $\mathrm{N}^{\circ} 1$, pp. 17-24, 1990.

LEJEUNE, M.: “Un Regard d'Ensemble sur le Marketing des Services", Revue Française du Marketing, vol. 121, n. 1, pp. 9-27, 1989.

MANRODT, K.B. \& DAVIS, Jr F.W.: "The Evolution to Service Response Logistics", International Journal of Physical Distribution \& Logistics Management, Vol. 22, $\mathrm{N}^{\circ}$ 9, pp. 3-10, 1992.

Mc LEAN, R. \& ANDERSON, V.L.: Applied Factorial and Fractional Designs, Marcel Dekker Inc, New York, 1984.
MORASH, E.A. \& OZMENT, J.: "Scheduling Management of Transportation Service Response Capacity to Improve Perceived Quality", Logistics and Transportation Review, vol. 31, n. 4, pp. 353-374, 1995.

MURPHY, P.R. et al.: "Port Selection Criteria: An Application of a Transportation Research Framework", The Logistics and Transportation Review, vol. 28, n. 3, pp 237-255, 1992.

NOVAES, A.G. \& ALVARENGA, A.C.: Logística Aplicada, Editora Pioneira, São Paulo, SP, 1994.

NOVAES, A.G.: “Análise de Mercado de Serviços de Transportes com Dados de Preferência Declarada", Anais do IX ANPET, vol 2, pp. 573584, São Carlos, SP, 20 a 25 de Novembro, 1995.

PORTER, M.E.: Estratégia Competitiva, Editora Campus, Rio de Janeiro, RJ, 1991.

VIEIRA, H.F.: "Uma Visão Empresarial do Processo de Exportação de Produtos Conteinerizados Catarinenses e Análise do Nível de Serviço Logístico", Dissertação de Mestrado, Departamento de Engenharia de Produção e Sistemas, UFSC, Florianópolis, SC, 1996.

\section{LOGISTICS SERVICE LEVEL OF PORT ACTIVITIES AS PERCEIVED BY EXPORTING INDUSTRIES}

\section{Abstract}

The export of manufatured products by Brazilian industries is burdenned by heavy land transportation costs and port expenses, in association with unsatisfactory logistics service levels when compared with similar conditions abroad. Costumers' full satisfaction has become a paradigm of modern Logistics. However, Brazilian port authorities have not tried to evaluate in a systematic way the users' opinions with respect to the services offered to them. In this paper we discuss the application of stated preference or conjoint analysis techniques to quantify the weights associated with the different factors that make up the service level in the exporting process of manufactured goods. The methodology is applied to the industries of the state of Santa Catarina, Brazil, which export products in containers through local ports.

Key words: service level, international trade logistics, conjoint analysis. 